\title{
Natural history of adrenal haemorrhage in the newborn
}

\author{
JOHN BLACK and DAVID INNES WILLIAMS \\ From The Hospital for Sick Children, London, and the Children's Hospital, Sheffield
}

\begin{abstract}
Black, J., and Williams, D. I. (1973). Archives of Disease in Childhood, 48, 183. Natural history of adrenal haemorrhage in the newborn. 5 cases of unilateral and 3 cases of bilateral haemorrhage are described. Only 1 infant died, from venous thromboses elsewhere. Apart from this case, all had an above average birthweight. Probable predisposing causes apart from large size were fetal hypoxia, septicaemia, thrombocytopenia, coagulation defect, and disseminated thromboembolic disease. The condition must be distinguished from renal vein thrombosis. In the acute stage pyelography shows depression of the kidney on the affected side, with flattening of the upper calyces. Calcification develops rapidly round the periphery of the mass, then slowly contracts into an area of the size and shape of the original gland. Treatment is with antibiotics and blood transfusion, with intravenous corticosteroids in severely shocked or bilateral cases. Adrenal insufficiency is rarely found on followup even in bilateral cases, but renal hypertension should be looked for. No single cause for the haemorrhage could be discovered, but the preponderance of haemorrhage into the right adrenal gland is probably due to anatomical differences between the venous drainage of the two sides.
\end{abstract}

Unilateral or bilateral haemorrhage into the adrenal gland is a common finding in stillbirths and in infants dying in the immediate postnatal period, but a massive haemorrhage into one or both glands, the so-called adrenal haematoma, is much less common. The cases described below illustrate the various ways in which the condition may present, and some of the difficulties in diagnosis and management. We report 8 cases, of which 7 survived; 3 of these infants had bilateral haemorrhage.

\section{Case reports (summaries in Table)}

Case 1. A male infant born after normal labour, birthweight $3.9 \mathrm{~kg}$, was admitted to a local hospital on the second day of life because of pallor which had followed the vomiting of fresh blood. On admission a few petechial haemorrhages were seen on the back and neck. A large mass was palpable in the right loin; Hb was $6.9 \mathrm{~g} / 100 \mathrm{ml}$. He was transfused. An intravenous pyelogram (IVP) showed no excretion of medium from either kidney. On the third day of life he was transferred to The Hospital for Sick Children, London. His blood urea was $87 \mathrm{mg} / 100 \mathrm{ml}$ and $\mathrm{Hb} 11.4 \mathrm{~g} / 100 \mathrm{ml}$; the urine contained $50 \mathrm{mg} / 100 \mathrm{ml}$ protein. A further $x$-ray of the abdomen showed that a delayed excretion of medium was taking place on the left side, but there was no excretion on the right side. A cystogram showed reflux up the right ureter into the pelvis; the right

Received 18 July 1972. kidney was depressed and the upper calyces were flattened (Fig. 1). At exploration, a little blood was found in the peritoneal cavity; there was a large adrenal haemorrhage with some extension into the retroperitoneal tissues. At the age of 7 months he appeared healthy and his parents were unwilling for any further investigations to be done.

No cause for the haemorrhage was established though a transient thrombocytopenia could not be excluded.

Case 2. A male was born after forceps delivery for a deep transverse arrest; birthweight $4 \cdot 6 \mathrm{~kg}$. At delivery no resuscitation was required, but later the same day he vomited and became pale and restless. He was transferred to the care of Mr. H. H. Nixon who found a mass on the right side of the abdomen. On admission $\mathrm{Hb}$ was $15 \cdot 7 \mathrm{~g} / 100 \mathrm{ml}$, but fell to $7 \cdot 7 \mathrm{~g} / 100 \mathrm{ml}$ on the 7 th day. Blood urea on admission was $120 \mathrm{mg} / 100 \mathrm{ml}$. An IVP showed only faint opacification of the renal substance on the right side. The urine contained protein,++ 6 to 8 white cells, and 8 to 12 red cells per high-power field.

Three weeks later a second IVP showed normal function of both kidneys: the right kidney was displaced downwards and laterally, and the adrenal mass was outlined by a ring of calcification (Fig. 2). At the age of 2 months (Fig. 3) there was increased calcification of the right adrenal, but the actual calcified area was considerably smaller; a few areas of calcification were also visible in the left adrenal area. An ACTH test showed a normal response. He made a complete recovery and at the age of 8 months was well. 
Details of 8 cases of adienc

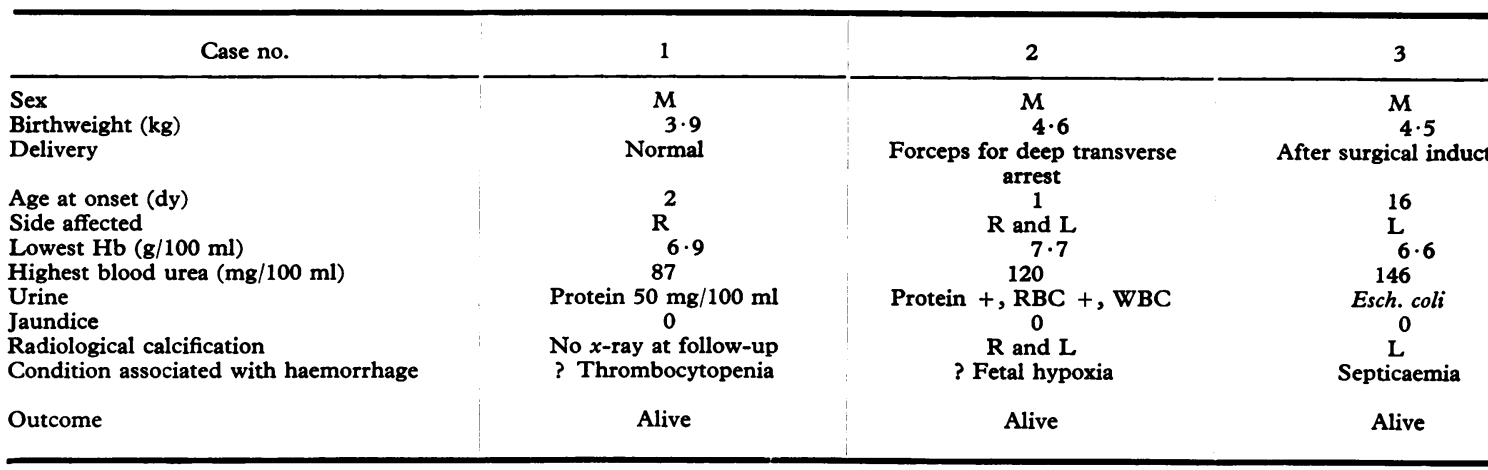

In this case, it seems likely that hypoxia or a prolonged delivery may have been factors in causing bilateral adrenal haemorrhage; the raised blood urea was probably due to renal ischaemia due to shock from loss of blood into the adrenals, possibly combined with a transient hypoadrenal state.

Case 3. A male infant was born after a surgical induction, birthweight $4.5 \mathrm{~kg}$. Progress was normal

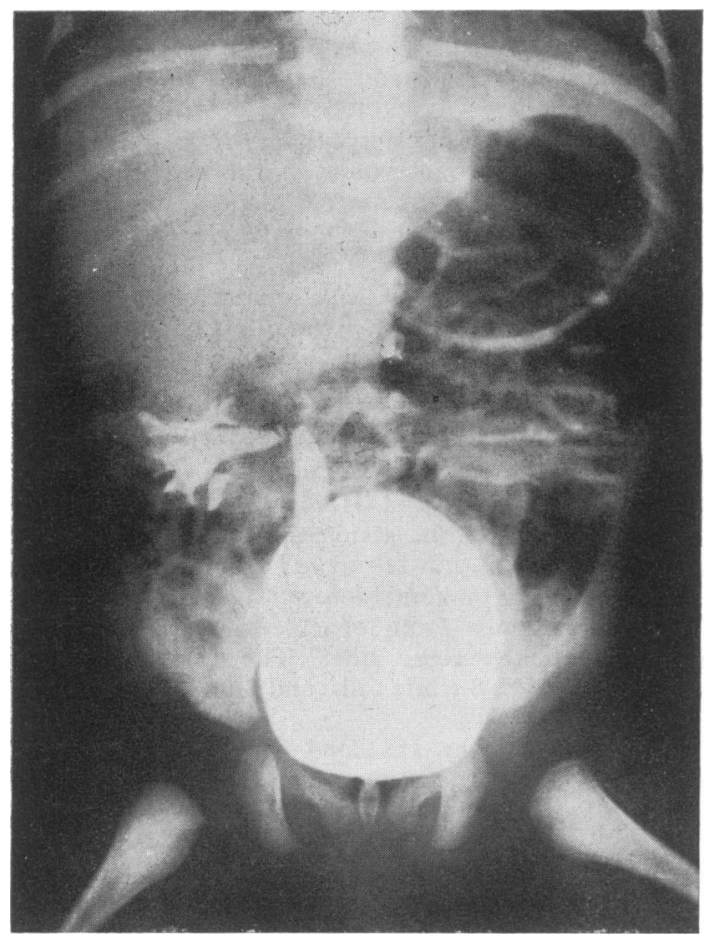

Fig. 1.-Case 1. Cystogram showing reflux up right ureter, downward displacement of the kidney, and flattening of upper calyces. until the 16th day of life when he became listless and had a number of fits. He was admitted to hospital in Exeter (Dr. F. S. W. Brimblecombe) where he was found to have a coliform meningitis. Initially, his blood urea was $146 \mathrm{mg} / 100 \mathrm{ml}$ and $\mathrm{Hb} 6.6 \mathrm{~g} / 100 \mathrm{ml}$; the urine was infected with Esch. coli. At the age of 10 weeks an IVP showed poor concentration in both kidneys and a large calcified area in the region of the left kidney. He was transferred to The Hospital for Sick Children, where a retrograde pyelogram showed that the left kidney was displaced downwards and laterally by a calcified mass (Fig. 4). At laparotomy the left adrenal was replaced by a mass adherent to both kidney and peritoneum. A biopsy from the mass showed that the normal structure of the gland had been almost completely destroyed by a haemorrhage but that there were a few islands of surviving adrenal cortical tissue in the calcified material. The surrounding fibrosis extended into the perirenal fat. When he was seen again for review at the age of 6 years, he was completely well apart from deafness which was attributed to the meningitis.

In this case the adrenal haemorrhage was unilateral and was perhaps related to a septicaemia.

Case 4. A male, born after a normal labour, birthweight $3.7 \mathrm{~kg}$, was unwell during the first week of life and appeared drowsy. On the 9 th day a mass was noted on the right side of the abdomen. IVP showed that the right kidney was depressed and displaced laterally. His blood urea was $26 \mathrm{mg} / 100 \mathrm{ml}$ and the urine contained numerous white cells but no red cells. At the age of 17 days he was transferred to The Hospital for Sick Children. On admission his right kidney was palpable but did not appear to be enlarged. Hb was $10 \mathrm{~g} / 100 \mathrm{ml}$. 4 days later a retrograde pyelogram showed displacement of the right kidney. At laparotomy the peritoneal cavity contained some old blood; the adrenal was explored and was found to be distended with a large amount of clotted blood. A biopsy showed extensive calcification and some surviving adrenal cortical tissue. He made an uneventful recovery and remained well. 


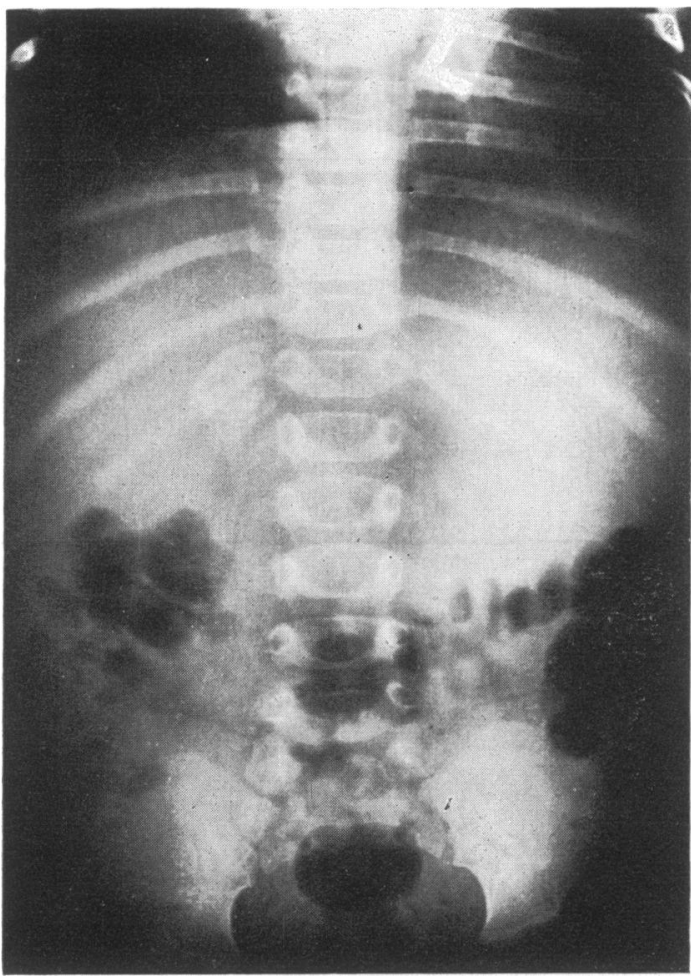

Fig. 3.-Case 2. A plain film of the abdomen at the age of 2 months showing shrinkage in size of the mass, compared with Fig. 2. In the original film small areas of calcification were also visible on the left side.

delivery, which could have caused hypotension and shock. The left kidney may have been damaged by a renal vein thrombosis associated with thrombosis of the left adrenal vein, or by a retrograde thrombosis along the inferior adrenal artery into the renal artery. The pyelonephritis probably developed in the already damaged kidney.

Case 6. A male, born after a normal labour, birthweight $3.8 \mathrm{~kg}$, became pale, vomited, and was reluctant to feed on the 3rd day of life. Next day the pallor was more marked and he appeared to be dehydrated. On the 6 th day $\mathrm{Hb}$ was $8.8 \mathrm{~g} / 100 \mathrm{ml}$ and there was slight jaundice (serum bilirubin $4.4 \mathrm{mg} / 100 \mathrm{ml}$ ). 10 days later a mass was palpable in the left loin, and he was transferred to The Hospital for Sick Children. He was found to be very pale ( $\mathrm{Hb} 6 \cdot 1 \mathrm{~g} / 100 \mathrm{ml}$; platelets were plentiful on a blood film), and he was bleeding from a prick in the left heel. Urine contained an excess of red cells but was otherwise normal; his blood urea was $29 \mathrm{mg} / 100 \mathrm{ml}$. Further investigation showed a prolonged prothrombin time ( 85 seconds, control 19 seconds): there was a moderate deficiency of Christmas factor (IX) but the level of antihaemophilic globulin (VIII) was normal. An intramuscular pyelogram showed

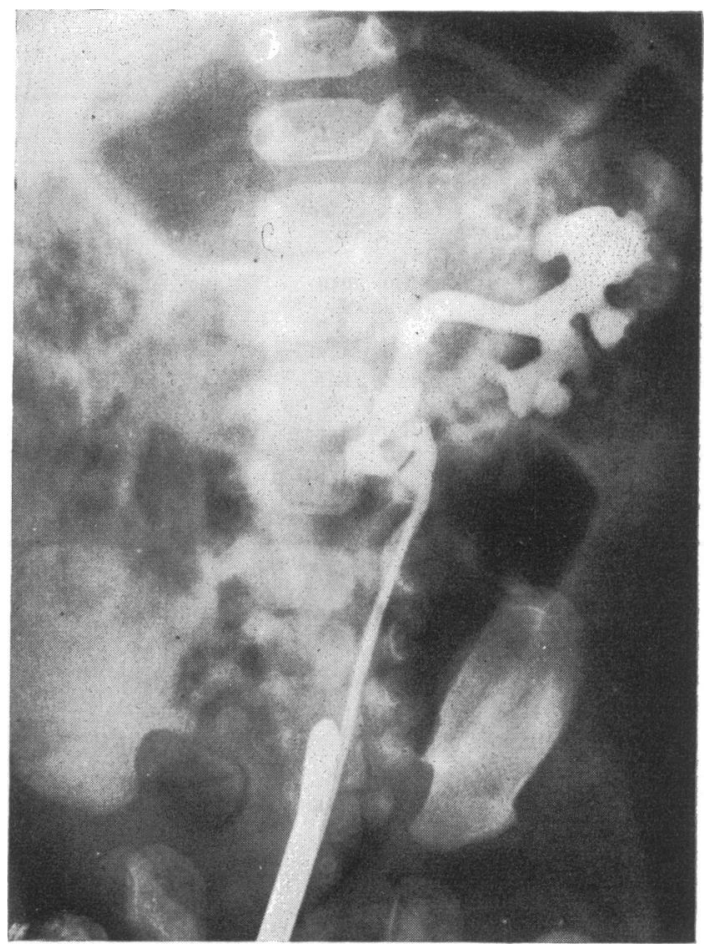

FIG. 4.-Case 3. Retrograde pyelogram at the age of 10 weeks showing a calcified area which has begun to shrink. The left kidney is rotated outwards.

good excretion by both kidneys; the upper calyces of the left kidney were flattened and the whole kidney was displaced downwards. After transfusion with fresh blood and treatment with intramuscular vitamin $K$, a laparotomy was performed. The left adrenal was found to be greatly enlarged by a haemorrhage into its substance. A frozen section from a biopsy showed some areas of normal adrenal tissue and the mass was not removed. A more detailed histological examination of the biopsy material showed extensive necrosis with haemorrhage and calcification, but the zona glomerulosa was still recognizable. He had no further bleeding episodes and at the age of 2 years he appeared well; an $x$-ray of the abdomen at this time showed no calcification.

In this case a transient haemorrhagic state was thought to be responsible for the adrenal haemorrhage.

Case 7. A male, born after a prolonged second stage, was admitted to Sheffield Children's Hospital (Dr. J. Lorber) at the age of 3 days with anuria and continuous convulsions. $\mathrm{He}$ appeared shocked and dehydrated, and a large mass was palpable in each loin. The urine contained a large number of urate crystals and $400 \mathrm{mg} / 100 \mathrm{ml}$ protein. His blood urea on admission was $150 \mathrm{mg} / 100 \mathrm{ml}$, rising to $230 \mathrm{mg} / 100 \mathrm{ml}$ on the following day: his serum calcium was persistently low $(4.9$ to $6.8 \mathrm{mg} / 100 \mathrm{ml})$, with a high inorganic phospho- 
rus $(9 \cdot 1 \mathrm{mg} / 100 \mathrm{ml})$. He was given intravenous fluids and calcium gluconate. His blood urea returned to normal by the 9th day. IVP at the age of 2 weeks showed downward displacement of both kidneys, kinking at the left pelviureteric junction, and dilatation of the lower third of the left ureter. Subsequent progress was uneventful apart from one episode of pyelonephritis which was successfully treated. At the age of 19 months a second IVP showed calcification of both adrenals (Fig. 5).

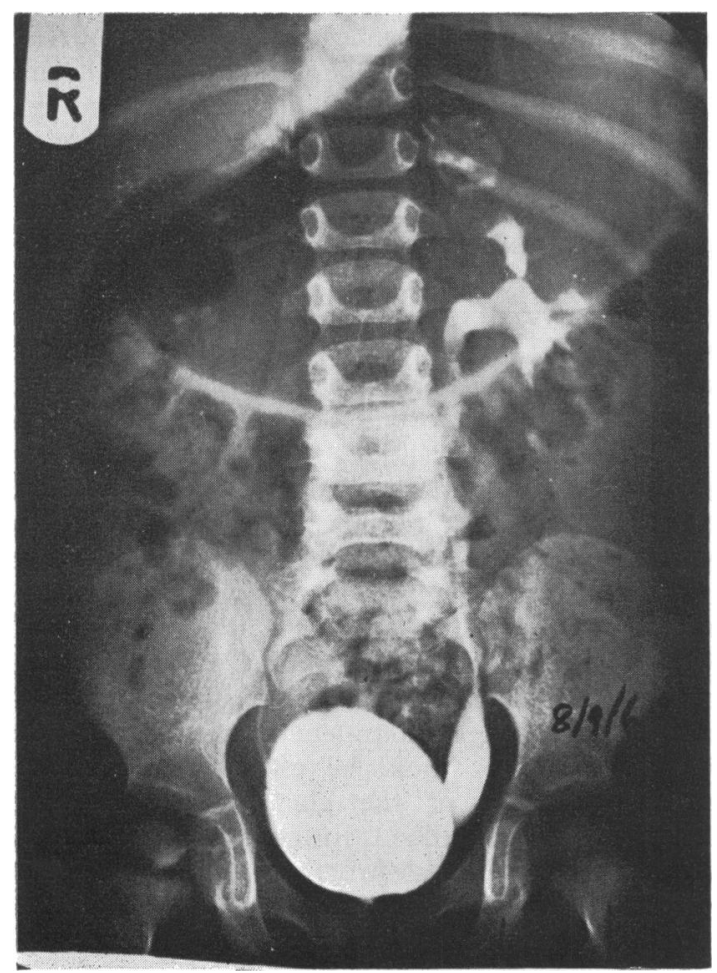

FIG. 5.-Case 7. Intravenous pyelogram at the age of 19 months showing some calcified areas on both sides of approximately the shape and size of the normal adrenal glands.

It seems clear that the abdominal masses were adrenal haematomata and not enlarged kidneys as was originally thought; the raised blood urea and anuria were almost certainly due to shock from loss of blood into the adrenals and possibly also due to a hypoadrenal state.

Case 8. A male, born by normal delivery, with a birthweight of $2 \cdot 7 \mathrm{~kg}$ was admitted to The Hospital for Sick Children on the 7th day of life because of anuria. There was marked ascites. At laparotomy the ascitic fluid was found to be blood stained, and there was a large retroperitoneal haemorrhage involving the right adrenal gland. Intestinal obstruction developed a few days later and at a second exploration the superior mesenteric vein was thrombosed. An enterostomy was done, but the infant died a few hours later. At necropsy there was extensive necrosis and haemorrhage of the right adrenal gland. There were two adrenal veins on the right side, the upper one being occluded by a calcified thrombus. There was also thrombosis of the distal end of the umbilical vein and of the intrahepatic portal vein, in addition to the superior mesenteric vein thrombosis previously observed.

In this case there were multiple thromboses, that in the adrenal vein being earlier than those involving the other veins. It seems likely that the infant's condition was due to a process of disseminated thromboembolism.

\section{Discussion}

Massive adrenal haemorrhage in the newborn usually occurs within the first few days after delivery. The infant becomes shocked or is pale and lethargic. By the time symptoms have appeared a mass is usually palpable in one loin or more rarely on both sides. There is an accumulation of a large volume of blood within the capsule of the gland, causing almost complete destruction of both cortex and medulla. The blood may leak into the tissues round the gland, and in some cases there is a considerable amount of blood in the peritoneal cavity. The clinical picture may mimic that of a ruptured liver (Hill and Williams, 1959). Reabsorption of the blood may cause transient jaundice, but this is not common. In one case (Corcoran and Strauss, 1924) the adrenal mass caused intestinal obstruction by pressure on the descending colon. The shock in unilateral cases is due to blood loss, but when both sides are involved acute adrenal failure may occur, and such infants may die within a few hours. Nevertheless, in this series 3 cases survived bilateral haemorrhage without the use of additional corticosteroids. The probable explanation for the survival is that biopsies taken at laparotomy have shown that even with a large haemorrhage small islands of adrenal cortical tissue may survive, usually in the subcapsular region (zona glomerulosa), and in any case both glands are rarely affected to the same degree; this may explain why an Addisonian type of picture with low serum sodium and raised potassium is not seen.

The kidneys may be involved in various ways. An acute pyelonephritis may occur as part of a septicaemia, or shock may cause ischaemic renal damage with anuria or oliguria and a raised blood urea. In other cases, the kidney could be involved in a vascular obstruction due to an extension of thrombosis in the adrenal vein into the renal vein, a possibility only on the left side in which the adrenal vein joins the renal vein; or a retrograde 
thrombosis could spread from the inferior adrenal artery into the renal artery.

The diagnosis of adrenal haemorrhage in the newborn is often difficult. The important distinction to be made is from renal vein thrombosis. The blood urea may be raised in both conditions, but in renal vein thrombosis naked-eye haematuria is usual, whereas a variable degree of proteinuria and a slight excess of red cells is common in adrenal haemorrhage. IVP in renal vein thrombosis shows no excretion on the affected side, while in adrenal haemorrhage the kidney is displaced downwards and rotated outwards, with flattening of the upper calyces (Fig. 1 and 4). However, in some cases of adrenal haemorrhage renal function is severely impaired during the early stages and opaque medium may not be concentrated on the affected side, or occasionally both sides. In such cases a retrograde pyelogram is necessary in order to show the characteristic appearance.

After recovery from the acute phase calcification of the gland occurs rapidly and may be visible within 3 or 4 weeks, or occasionally as early as 12 days after the haemorrhage (Wagner, 1961). Characteristically, the calcification which develops round the periphery of the mass of blood and necrotic adrenal tissue is visible as a thin line (Fig. 2). As the blood is reabsorbed the area of calcification shrinks (Fig. 3 and 4) and the opacity finally becomes concentrated into an area corresponding to the shape and size of the original gland (Fig. 5). Once calcification has developed it probably persists for life, since it is quite a common incidental finding in children and adults. There is rarely much difficulty in distinguishing the abdominal mass due to calcified adrenal haemorrhage from that of a neuroblastoma, since in adrenal haemorrhage there is usually a history of shock and pallor shortly after delivery and the calcification encircles the mass.

Treatment depends upon the severity of the illness; resuscitation with blood or intravenous fluids may have to precede an accurate diagnosis. Blood and urine should be taken for culture in all acute cases and treatment with antibiotics should be started immediately. Vitamin $\mathrm{K}$ should be given intravenously or intramuscularly in all severely ill cases, but further investigation will be required to exclude thrombocytopenia or a haemorrhagic state. If the diagnosis can be made with confidence, large doses of hydrocortisone should be given in all bilateral cases or in any cases which do not respond adequately to blood or intravenous fluids. Corticosteroids should always be given if a general anaesthetic is required for a retrograde pyelogram or laparotomy. A diagnostic laparotomy is rarely, if ever, required since the correct diagnosis can usually be made by pyelography and by observing the gradual shrinkage in size of the abdominal mass, which does not occur in a renal or adrenal tumour. If a laparotomy is thought to be necessary, the entire adrenal mass should not be removed since there is invariably some surviving cortical tissue.

In the children whom we have observed, the sequelae have been remarkably few; an adrenal stimulation test should be done in all bilateral cases. In Gardner's (1957) cases the adrenal insufficiency which developed did not appear to involve the salt-retaining hormone, and this may be related to the fact that it is usually the zona glomerulosa which survives (our series, Cases 1, $3,4)$; it is of interest that hypoglycaemia is usually the only symptom in those children who have symptoms. The finding of hypertension in one child, due to unilateral renal disease, nevertheless emphasizes the importance of a careful follow-up.

Numerous suggestions have been made to explain the susceptibility of the adrenal gland to haemorrhage, and to massive haemorrhage in particular. The arterial supply comes from 3 main trunks and from numerous small arterial twigs (Gagnon, 1957), so that infarction of the whole gland from interruption of its arterial supply is virtually impossible (Fox, 1969a). As in the kidney, complete obstruction to the venous drainage would be expected to produce rapid distension of the gland from continued entry of arterial blood, progressing to massive haemorrhage and destruction of tissue. The picture of massive haemorrhage into the adrenal gland is in fact very similar to that seen in renal vein thrombosis.

Small haemorrhages into the adrenal gland are a common finding in the newborn infant; they usually occur at the junction of the fetal zone with the definitive cortex (Hill and Williams, 1959; Kissane and Smith, 1967) and may be related to the involution of the fetal zone which occurs shortly after delivery. Recently Boyd $(1966,1967)$ has shown that disseminated thromboembolic lesions are found in a proportion of stillbirths and also in infants dying within the first 48 hours after birth. Such lesions in the adrenal glands were more frequent in the second group and consisted of fibrinous masses in the cortical capillaries, in the medullary sinuses, or in the central vein itself; haemorrhage involving the whole gland only occurred in one case. These findings give little indication as to the cause of massive haemorrhage. 
Apart from the presence of a fetal zone, the adrenal gland of the newborn infant differs from the adult gland in other respects. Velican (1947) described the so-called 'vascular dam' consisting of narrow channels passing from cortex to medulla, and it has been suggested that these channels could easily be obstructed by distortion or compression, and so cause haemorrhage within the gland. However, Velican did not find such an arrangement in the gland of the newborn. Another difference between the adult gland and that of the newborn is that the bundles of longitudinal smooth muscle fibres, which in the adult are found in the adrenal (extraglandular) vein, the central (intraglandular) vein, and its medullary branches, are virtually absent in the newborn infant (Bargmann, 1933; Heinivaara, 1954). The function of these muscle bundles has been much disputed (Velican, 1948; Dobbie and Symington, 1966), but Heinivaara suggested that contraction of their fibres would narrow the lumen of the adrenal vein and act as a protection against a sudden transient increase in pressure in the inferior vena cava, such as might occur with abdominal compression; he also pointed out that the renal vein had a similar structure. The effective absence of these muscle bundles in the newborn would make the adrenal gland particularly susceptible to venous congestion from fluctuations in pressure in the inferior vena cava occurring during delivery. Browne (1922) found that difficult forceps delivery and breech delivery were commonly associated with extensive rather than massive haemorrhage in stillbirths.

It has been shown on many occasions that the adrenal gland is to some extent protected against damage from obstruction to its main venous outflow when thrombosis of the central vein occurs. Kutschera-Aichbergen (1922) was one of many authors to draw attention to a system of centrifugal veins running from the medulla through the cortex and emptying into a plexus of veins on the capsule of the gland. Dobbie and Symington (1966) showed by injection studies that these 'emissary veins' can be of considerable size. The importance of this safety route of venous drainage was shown by Fox $(1969 a, b)$ who found that massive haemorrhage into the gland was more likely to occur when the capsular venous system was thrombosed in addition to thrombosis of the central vein, but that central vein thrombosis alone did not necessarily produce haemorrhage.

In a review of 33 cases of massive adrenal haemorrhage Hill and Williams (1959) found that the right side only was involved in 6 out of 10 surviving and in 18 out of 23 fatal cases $(72 \%$ of all cases); of our own series, in 3 out of 8 infants the haemorrhage occurred only on the right side. In adults, Sevitt (1955) found that massive haemorrhage was relatively common on the right side after direct thoracoabdominal trauma. The explanation for the difference in susceptibility to massive haemorrhage between the two sides appears to lie in their venous drainage (Gagnon, 1955-56). The right adrenal drains directly into the inferior vena cava without contribution from any other vein, and its capsular system also drains into the inferior vena cava, apart from a small and probably unimportant anastomosis with the portal system through Glisson's capsule (Kutschera-Aichbergen, 1922); communication with the azygos vein is very rare (Gagnon, 1955-56). Thus the right adrenal, though protected against thrombosis of its central vein, would suffer severe venous engorgement as a result of a prolonged rise in pressure in the inferior vena cava which would obstruct the venous return through both central and capsular veins. On the left side the adrenal vein joins the renal vein which also receives the first lumbar and internal spermatic (or ovarian) veins and there is frequently a communication with the hemiazygos vein which drains into the superior vena cava. In addition, the capsular venous system has an anastomosis with the portal vein via the body of the pancreas (Kutschera-Aichbergen, 1922). Thus a rise in pressure in the inferior vena cava would cause passive distension of the veins entering the renal vein and diversion of blood through the hemiazygos into the superior vena cava, the first lumbar vein into the lumbar vein system, and through the capsular veins into the portal vein. The left adrenal is therefore well supplied with alternative channels in the event of temporary or permanent obstruction at the level of the inferior vena cava but is nevertheless at risk if the left renal vein becomes thrombosed, so that both kidney and adrenal may be involved. It is of interest that KutscheraAichbergen was able to inject the venous system of the left adrenal without difficulty but on the right side injection, even at low pressure, was impossible without damaging the gland.

In this series of 8 cases all were male and in Hill and Williams' review there were 16 males of the 21 cases where the sex was stated. Hill and Williams attributed the preponderance of males to the larger birthweight of male infants, but in the perinatal survey Butler and Bonham (1963a) found an excess of male over female deaths for every birthweight group, and in the necropsy study (Butler and Bonham, 1963b) they found that massive pulmonary haemorrhage, intraventricular 
haemorrhage, cerebral birth trauma with intrapartum hypoxia, and cerebral birth trauma alone were twice as common in males as in females. It is therefore difficult to be certain whether the sex difference in adrenal haemorrhage merely reflects the generally increased susceptibility of the male newborn infant to a variety of disasters, or whether there is some more specific but unknown cause for the difference. Certainly in our series all but one infant had large birthweights and such large infants may undergo more abdominal compressions during delivery than do small infants.

From the evidence presented above it seems unlikely that massive adrenal haemorrhage is due to any single process. Small haemorrhages and thromboses are common, but an additional factor is probably required to convert the initial lesion into a massive haemorrhage. Such additional factors are likely to be prolonged abdominal compression during delivery, thrombocytopenia from septicaemia or other causes, or a haemorrhagic state of any sort including hypofibrinogenaemia due to disseminated thromboembolic lesions.

We wish to acknowledge the help of Drs. F. S. W. Brimblecombe, J. Rubie, R. Lightwood, J. Lorber, D. G. Vulliamy, and Mr. H. H. Nixon for making available clinical details of their cases.

\section{REFERENCES}

Bargmann, W. (1933). Uber den Bau der Nebennierenvenen des Menschen und der Saügetiere. Zeitschrift für Zellforschung und mikroskopische Anatomie, 17, 118.

Boyd, J. F. (1966). Disseminated fibrin thromboembolism in stillbirths: a histological picture similar to one form of maternal hypofibrinogenaemia. fournal of Obstetrics and Gynaecology of the British Commonwealth, 73, 629.

Boyd, J. F. (1967). Disseminated fibrin thromboembolism among neonates dying within $\mathbf{4 8}$ hours of birth. Archives of Disease in Childhood, 42, 401.
Browne, F. J. (1922). Neonatal death. British Medical fournal, 2, 590 .

Butler, N. R., and Bonham, D. G. (1963a). Perinatal Mortality, p. 132, table 42. Livingstone, Edinburgh and London.

Butler, N. R., and Bonham, D. G. (1963b). Perinatal Mortality, p. 268, table 84. Livingstone, Edinburgh and London.

Corcoran, W. J., and Strauss, A. A. (1924). Suprarenal haemorrhage in the newborn. Fournal of the American Medical Association, 82, 626.

Dobbie, J. W., and Symington, T.* (1966). The human adrenal gland with special reference to the vasculature. Fournal of Endocrinology, 34, 479.

Fox, B. (1969a). Unilateral adrenal necrosis and haemorrhage following operations on the stomach. Fournal of Pathology, $97,127$.

Fox, B. (1969b). Adrenal haemorrhage and necrosis resulting from abdominal operations. Lancet, 1, 600 .

Gagnon, R. (1955-56). The venous drainage of the human adrenal gland. Révue Canadienne de Biologie, 14, 350.

Gagnon, R. (1957). The arterial supply of the human adrenal gland. Révue Canadienne de Biologie, 16, 421.

Gardner, L. T. (1957). Newer knowledge of adrenocortical disturbances. Pediatric Clinics of North America, 4, 889.

Heinivaara, $O$. (1954). On the structure of the human suprarenal vein. Annales Medicinae Internae Fenniae, 43, Suppl. 19.

Hill, E. E., and Williams, J. A. (1959). Massive adrenal haemorrhage in the newborn. Archives of Disease in Childhood, 34, 178.

Kissane, J. M., and Smith, M. G. (1967). Pathology of Infancy and Childhood, p. 695 . Mosby, St. Louis.

Kutschera-Aichbergen, H. (1922). Nebennierenstudien. Frankfurter Zeitschrift fiir Pathologie, 28, 262.

Sevitt, S. (1955). Post-traumatic adrenal apoplexy. Fournal of Clinical Pathology, 8, 185.

Velican, C. (1947). Le barrage vasculaire cortico-médullaire de la surrénale de l'homme. Annales d'Endocrinologie, 8, 495.

Velican, C. (1948). Le dispositif sphinctéro-propulseur de la surrénale. Archives d'Anatomie Microscopique et de la Morphologie Expérimentale, 37, 28.

Wagner, A. C. (1961). Bilateral haemorrhagic pseudocysts of the adrenal glands in a newborn. American fournal of Roentgenology, 86, 540 .

Correspondence to Dr. J. A. Black, The Children's Hospital, Western Bank, Sheffield S10 2TH.

*This subject is dealt with more fully in Symington, T. (1969). Functional Pathology of the Human Adrenal Gland. Livingstone, Edinburgh. 